\title{
Ocena funkcji motorycznych chorego z SMA Illb poddanego fizjoterapii z jednoczesnym leczeniem lekiem Nusinersen - opis przypadku
}

\section{Assessment of motor functions in a patient with SMA IIIb undergoing physiotherapy with simultaneous treatment with Nusinersen - a case study}

\author{
Maciej R. Raczak (D), Lech Furmaniuk (iD) \\ Zakład Rehabilitacji Narządu Ruchu AWF Poznań, ul. Królowej Jadwigi 27/39 61-871 Poznań \\ DOI:10.20966/chn.2020.59.474
}

\section{STRESZCZENIE}

Praca przedstawia zmiany w funkcjach motorycznych pacjenta z rdzeniowym zanikiem mięśni (SMA) Illb w wyniku prowadzonej fizjoterapii i farmakoterapii lekiem Nusinersen (Spinraza).

Zakres zmian monitorowano na podstawie analizy wyników punktacji przy użyciu skali Hammersmith Functional Motor Scale Expanded (HFMSE). Przy wykonywaniu testów z użyciem skali HFMSE badany był oceniany w trzystopniowej skali, składającej się z trzydziestu trzech czynności, mających na celu klasyfikację funkcjonalną osób z SMA III.

W początkowym badaniu zaobserwowano wynik w skali HFMSE na poziomie 24 punktów z 66 możliwych do zdobycia. Wzrost zanotowano po sześciu miesiącach leczenia oraz prowadzonej fizjoterapii z 24 na 28 punktów, zmiany nastapiły w testach dotyczących funkcji zmiany pozycji z leżenia tyłem do leżenia przodem i odwrotnie. Następny wzrost wystąpił po trzech miesiącach z 28 na 31 punktów, zmiany nastąpiły w testach dotyczących funkcji podporu ciała oraz zmiany pozycji z leżenia tyłem do siadu. Ostatni wzrost zaobserwowano po kolejnych trzech miesiącach z 31 na 34 punkty, zmiany nastąpiły w testach dotyczących funkcji wejścia do pozycji czworaczej oraz przemieszczania się w niej.

Po przeanalizowaniu wniosków oraz porównaniu ich z opublikowanymi w artykułach naukowych wyników badań klinicznych, zaobserwowano wzrost funkcji motorycznych w skali HFMSE u pacjenta z SMA Illb w wyniku prowadzonej fizjoterapii wspomaganej terapią lekiem Nusinersen.

Słowa kluczowe: SMA, Nusinersen (Spinraza), fizjoterapia, funkcje motoryczne, HFMSE
ABSTRACT

The paper presents changes in the motor functions of a patient with spinal muscular atrophy (SMA) IIlb as a result of physiotherapy supported by Nusinersen (Spinraza) therapy.

The extent of the changes was monitored by analyzing the scores using the Hammersmith Functional Motor Scale Expanded (HFMSE). When testing with the HFMSE scale, the subject was assessed on a three-point scale consisting of thirty-three activities aimed at functional classification of people with SMA III. In the initial study the HFMSE score was 24 out of 66 possible. The increase from 24 to 28 points was noted after six months of treatment and physiotherapy, the changes occurred in the tests of the function of changing the position from supine to prone and vice versa. The next increase from 28 to 31 points occurred after three months, the changes occurred in the tests of the body support function and the change of position from supine to sitting. The last increase from 31 to 34 points was observed after the next three months, the changes took place in the tests of the function of entering the quadruple position and moving in it.

After analyzing the conclusions and comparing them with the results of clinical trials published in scientific articles, an increase in motor functions in the HFMSE scale was observed in a patient with SMA IIlb as a result of physiotherapy supported by Nusinersen therapy.

Key words: SMA, Nusinersen (Spinraza), physiotherapy, motor functions, HFMSE

\section{WSTĘP}

Rdzeniowy zanik mięśni to grupa chorób dziedzicznych, których wspólną cechą jest zanik motoneuronów alfa rdzenia kręgowego, rezultatem czego jest wiotkość oraz osłabienie siły mięśniowej. Typy tej choroby charakteryzują się podobnymi objawami, różnią się natomiast ich stopniem nasilenia oraz obszarem występowania. Rdzeniowy zanik mięśni (z ang. SMA - spinal muscular atrophy), występuje z częstością 1:10 000 urodzeń. Podłożem etiologicznym jest mutacja genu SMN1. Występuje ona w postaciach: SMA 0, SMA I, SMA II, SMA IV oraz SMA III (zwa- nej inaczej chorobą Kugelberg-Welander), która występuje w typach IIIa oraz IIIb. W SMA IIIa pierwsze objawy choroby pojawiają się przed trzecim rokiem życia, są one bardziej wyraźne niż w typie IIIb. W SMA IIIb pierwsze objawy pojawiają się po trzecim roku życia i mogą być długo niezauważalne [1-3].

Leczenie fizjoterapeutyczne $\mathrm{w}$ rdzeniowym zaniku mięśni SMA III polega na hamowaniu następstw choroby poprzez zastosowanie zabiegów fizjoterapeutycznych składających się z: terapii oddechowej, ćwiczeń mobilno- 
ści, rozciągania, terapii w odciążeniu (Dunag 02), terapii neurorozwojowych; w tym między innymi metody proprioceptywnego nerwowo-mięśniowego torowania ruchu (z ang. PNF - Proprioceptive Neuromuscular Facilitation), terapii tkanek miękkich oraz masażu; zabiegów fizykalnych oraz aktywnej rehabilitacji na wózku inwalidzkim. Przedstawione metody fizjoterapeutyczne mają utrzymać zdolności pacjenta do wykonywania czynności dnia codziennego ( $\mathrm{z}$ ang. ADL - Activities of Daily Living). Dzieje się to poprzez poprawę funkcji motorycznych [4-7].

Fizjoterapia w SMA powinna być prowadzona równolegle z terapią farmakologiczną. Obecnie w Polsce istnieje możliwość stosowania leku Nusinersen, czyli antysensownego oligonukleotydu (z ang. ASO - Antisense Oligonucleotide). Działanie leku polega na modyfikacji genu SMN2. Co prowadzi do zwiększenia syntezy długołańcuchowego białka SMN (z ang. Survival Motor Neuron) i normalizacji procesu rozwoju funkcji motorycznych, zahamowania regresu rozwoju układu nerwowo-mięśniowego, zmniejszenia ryzyka konieczności stosowania wentylacji mechanicznej oraz podniesienie jakości życia [8-10].

\section{CEL PRACY}

Przedstawienie zmian $\mathrm{w}$ rozwoju funkcji motorycznych pacjenta $\mathrm{z}$ SMA IIIb w wyniku prowadzonej fizjoterapii z jednoczesnym stosowaniem leczenia przy użyciu Nusinersenu.

\section{Omówienie przypadku}

W badaniach udział wziął 11 letni chłopiec, u którego w wieku 3 lat zdiagnozowano SMA IIIb. Urodzony z ciąży prawidłowej; porodem prawidłowym; z masą urodzeniową 3790 gram. W skali Apgar uzyskał 10 punktów.

Badany wraz z prawnymi opiekunami wyrazili zgodę na udział w badaniu.

$\mathrm{W}$ toku osiągania swoich kamieni milowych rozwoju ruchu badany: siadał od około 7 miesiąca życia oraz chodził od około 13 - 14 miesiąca życia. Dopiero od około 2 roku życia pogorszył się u niego chód (częste upadki) natomiast w wieku 2,5 roku przestał w ogóle chodzić.

$\mathrm{W}$ momencie rozpoczęcia farmakoterapii, najwyższą funkcją motoryczną u pacjenta był siad prosty bez wsparcia kończynami górnymi; badany nie czworakował, dodatkowo miał trudności ze zmianą pozycji z leżenia przodem do leżenia tyłem i odwrotnie. Nie był w stanie przyjąć pozycji stojącej oraz nie chodził. Przemieszczał się przy pomocy aktywnego wózka inwalidzkiego [1-3, 9].

U badanego zaobserwowano następujące objawy: osłabienie mięśni obręczy biodrowej, fascykulacje mięśni kończyn dolnych (szybkie i drobne skurcze grup włókien mięśniowych) oraz osłabienie odruchów kolanowych oraz skokowych $[9,10]$.

\section{Dawkowanie leku Nusinersen}

Farmakoterapia lekiem Nusinersen trwała wówczas rok. Lek podawany był drogą punkcji lędźwiowej zgodnie $\mathrm{z}$ charakterystyką produktu leczniczego, tj. w dawkach: 1) wysycających, pierwsze trzy podania w przedziałach czasowych od dwóch do trzech tygodni; 2) podtrzymujących - podawanych co cztery miesiące.

\section{Postępowanie fizjoterapeutyczne}

Podczas 13 miesięcznej obserwacji badany brał udział w comiesięcznych zajęciach terapeutycznych obejmujących:

- Osiem sesji fizjoterapeutycznych (2 tygodniowo) na początku i na końcu każdego tygodnia, każdej trwającej półtorej godziny. Stosowano terapię metodami PNF, Bobath oraz Dunag 02., które miały na celu: pobudzenie proprioreceptorów pacjenta; hamowanie patologicznych odruchów oraz torowanie prawidłowych sekwencji rozwoju psychomotorycznego; odciążenie układu mięśniowego badanego [4-7].

- Cztery sesje indywidualnych zajęć terapii w wodzie, jeden raz w tygodniu; każdej trwającej jedną godzinę i obejmujących naukę pływania metodą Halliwick w celu oswojenia się badanego ze środowiskiem wodnym oraz naukę samodzielnego poruszania się w wodzie. Dodatkowo terapia w wodzie pozwoliła na rozluźnienie układu mięśniowego badanego [11].

- Dwie sesje grupowych zajęć aktywnej rehabilitacji, w pierwszą i drugą sobotę każdego miesiąca; każdej trwającej trzy godziny. Sesje te obejmowały ćwiczenia: z techniki jazdy na aktywnym wóz$\mathrm{ku}$ inwalidzkim, ogólno kondycyjne oraz z piłkami do koszykówki. Stosowano je w celu rozwoju motoryki dużej; polepszenia: wydolności mięśnia sercowego, obwodowego krążenia krwi, wydajności transportu tlenu, siły mięśni oddechowych, wentylacji płuc, wydajności mięśni szkieletowych; zwiększenie samodzielności w czynnościach dnia codziennego [12].

Przy wprowadzeniu tak szerokiego zakresu fizjoterapii niezbędne było uwzględnienie odpowiednio dostosowanych przerw, pozwalających badanemu na regenerację.

Przed rozpoczęciem obserwacji u badanego zmierzono zakres ruchów w stawach. Wyniki wykazały, iż zakresy biernych ruchów w stawach mieściły się w normie. Natomiast zakresy ruchów czynnych w stawach znajdowały się poniżej norm, było to spowodowane osłabieniem siły mięśniowej badanego. Na tej podstawie stwierdzono u badanego brak przykurczów.

W czasie trwania obserwacji badany nie brał udziału w żadnych dodatkowych sesjach ani turnusach terapeutycznych poza wyżej wymienionymi.

W okresie obserwacji trwającym 12 miesięcy badany był co miesiąc poddawany ocenie funkcjonalnej przy użyciu zwalidowanej skali Hammersmith Functional Motor Scale Expanded (HFMSE). Badania wykonywano po zakończeniu wszystkich sesji terapeutycznych z danego miesiąca [13-16].

Skala HFMSE to narzędzie diagnostyczne służące do oceny zdolności motorycznych osób z rdzeniowym zanikiem mięśni. Jej oryginalna wersja, czyli Hammersmith 
Functional Motor Scale (HFMS) została rozszerzona o 13 dodatkowych funkcji pochodzących z Gross Motor Function Measure (GMFM). Badane funkcje podlegały ocenie w trzypunktowej skali: ocena na 0 punktów - kiedy badany nie wykonał zadanej czynności; ocena na 1 punkt - kiedy badany wykonał zadaną czynność przy pomocy kompensacji; ocena na 2 punkty - kiedy badany w pełni wykonał zadaną czynność. Minimalna różnica istotna klinicznie dla skali HFMSE wynosi $\geq 2$ punkty [13-16].

Pomiędzy 10 badaniem (29.02.2020) a 11 badaniem (30.05.2020) nastąpiła trzymiesięczna przerwa z powodu sytuacji epidemiologicznej związanej z pandemią COVID -19.

W Tabeli nr I przedstawiono 17 z 33 badanych przez skalę HFMSE funkcji, w których zaobserwowano zmianę. W pozostałych funkcjach nie doszło do zmian.

Wyniki testów dotyczących zmiany pozycji z leżenia tyłem do leżenia przodem i odwrotnie w początkowej ocenie były na poziomie 1 punktu. Wzrost do poziomu 2 punktów nastąpił przy 7 badaniu. Wyniki testów dotyczących podporu na wyprostowanych kończynach górnych w leżeniu przodem oraz zmiany pozycji z leżenia tyłem do siadu w początkowej ocenie były na poziomie 1 punktu. Wzrost do poziomu 2 punktów nastąpił przy 10 badaniu. Wynik testu dotyczącego przyjęcia pozycji czworaczej w początkowej ocenie był na poziomie 0 . Wzrost do poziomu 1 punktu nastąpił przy 10 badaniu, natomiast wzrost do poziomu 2 punktów nastąpił przy 11 badaniu. Wynik testu dotyczącego przemieszczania się w pozycji czworaczej w początkowej ocenie był na poziomie 0 . Wzrost do poziomu 2 punktów nastąpił przy 11 badaniu.

\section{DYSKUSJA}

We wszystkich przedstawionych poniżej badaniach stwierdzono zmianę w funkcjach motorycznych na podstawie analizy progresu wyników w skali HFMSE, której użyto do monitorowania terapii. Czas trwania tych badań był we wszystkich przypadkach do siebie podobny [13-16].

W badaniu własnym trwającym 13 miesięcy, badanemu z SMA IIIb podano sześć dawek leku Nusinersen, każdorazowo zawierającej $12 \mathrm{mg}$ substancji czynnej. W tym czasie zanotowano u niego wzrost punktacji w skali HFMSE z 24/66 do 34/66 punktów, przekraczając w ten sposób próg minimalnej różnicy istotnej klinicznie. Świadczyło to o wzroście jego funkcji motorycznych a co za tym idzie jego samodzielność oraz zdolność do wykonywania czynności dnia codziennego. W czasie trwania obserwacji nie wystąpiły u niego żadne zdarzenia ani działania niepożądane [13-16].

W badaniu klinicznym 1 fazy trwającym 14 miesięcy przeprowadzonym na 28 pacjentach z SMA II oraz III, 10 z nich podano pojedynczą dawkę leku Nusinersen zawierającą $9 \mathrm{mg}$ substancji czynnej, pozostali uczestnicy otrzymali dawkę $1 \mathrm{mg}$ lub $6 \mathrm{mg}$. W toku trwania badania w grupie, której podano dawkę $9 \mathrm{mg}$ zaobserwowano średni wzrost punktacji w skali HFMSE na poziomie 5.8 punktu [13-17].
W badaniu klinicznym 3 fazy o akronimie CHERISH trwającym 15 miesięcy wzięło udział 126 pacjentów z SMA II oraz III. Spośród, których 84 zakwalifikowano do grupy badawczej, której podano cztery dawki leku Nusinersen, każdorazowo zawierającej $12 \mathrm{mg}$ substancji czynnej. W czasie trwania badania zaobserwowano u badanych średni wzrost punktacji w skali HFMSE na poziomie 3.9 punktu [8, 13-16].

W obydwu badaniach klinicznych wyniki uczestników przekroczyły próg minimalnej różnicy istotnej klinicznie. Efektem tego był wzrost funkcji motorycznych u badanych. W czasie trwania obserwacji u żadnego z uczestników wyżej wymienionych badań klinicznych nie wystąpiły żadne poważne zdarzenia ani działania niepożądane [8, 10, 13-17].

\section{WNIOSKI}

Po porównaniu finalnych wyników badanego z tymi sprzed trwającej rok terapii fizjoterapeutycznej wspomaganej leczeniem farmakologicznym, zaobserwowano u niego wzrost funkcji motorycznych oraz ich dalszą tendencję wzrostową. Potwierdza się więc to, że skala HFMSE pozwala na dokładną obserwację zmian w funkcjach motorycznych u pacjenta z SMA IIIb. Oznacza to zatem, że planowanie terapii w oparciu o zmiany w tej skali może pozwolić na zaplanowanie realistycznych oraz długofalowych celów terapeutycznych.

\section{PIŚMIENNICTWO}

[1] D'Amico A., Mercuri E., D Tiziano F., et al.: Spinal muscular atrophy. Orphanet Journal of Rare Diseases 2011; 6: 71.

[2] Zerres K., Rudnik-Schöneborn S., Forrest E., et al.: A collaborative study on the natural history of childhood and juvenile onset proximal spinal muscular atrophy (type II and III SMA): 569 patients. Journal of the Neurological Sciences 1997; 146: 67-72.

[3] Saniewska E., Saniewska N.: Wiedza pacjentów obciążonych rdzeniowym zanikiem mięśni (SMA) oraz ich opiekunów na temat choroby. PRYMAT, Białystok 2019.

[4] Tomczyński J., Werner B., Bartosiak I.: Fizjoterapia dzieci z rdzeniowym zanikiem mięśni. Pediatria Polska 2011; 86: 82-85.

[5] Małachowska-Sobieska M., Demczuk-Włodarczyk E., Wronecki K., et al.: Orteza dynamiczna Dunag 02. Fizjoterapia 2013; 21: 45-61.

[6] Dunaway S., Montes J., McDermott M., et al.: Physical therapy services received by individuals with spinal muscular atrophy (SMA). JPRM 2016; 9: 35-44.

[7] Adler S., Beckers D., Buck M.: PNF in Practice. An Illustrated Guide. Springer-Verlag Berlin Heidelberg, Heidelberg 2008.

[8] Darras B. T., Farrar M. A., Mercuri E., et al.: An Integrated Safety Analysis of Infants and Children with Symptomatic Spinal Muscular Atrophy (SMA) Treated with Nusinersen in Seven Clinical Trials. CNS Drugs 2019; 33: 919-931.

[9] Grędowska E., Modrzejewska S., Mazurkiewicz-Bełdzińska M.: Nusinersen w leczeniu rdzeniowego zaniku mięśni - praca poglądowa. Child Neurology 2019; 28: 17-21.

[10] Jędrzejowska M., Kostera-Pruszczyk A.: Rdzeniowy zanik mięśni - nowe terapie, nowe wyzwania. Child Neurology 2017; 26: 11-17.

[11] Cunhal M. C. B., Oliveira A. S. B., Labronici R. H. D. D., et al.: Spinal muscular atrophy type II (intermediary) and III (Kugelberg-Welander): Evolution of 50 patients with physiotherapy and hydrotherapy in a swimming pool. Arq. Neuro-Psiquiatr 1996; 54: 402-406.

[12] Divanoglou A., Tasiemski T., Augutis M., et al.: Active Rehabilitation a community peer-based approach for persons with spinal cord injury: international utilisation of key elements. Spinal Cord 2019; 57: 897-905. 


\begin{tabular}{|c|c|c|c|c|c|c|c|c|c|c|c|c|c|c|c|c|c|c|}
\hline 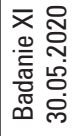 & $\sim$ & $N$ & $\sim$ & $\sim$ & $\sim$ & $\sim$ & $\sim$ & $\sim$ & $\sim$ & $\sim$ & $\sim$ & $\sim$ & $\sim$ & $\sim$ & $\sim$ & $\sim$ & $N$ & |户 \\
\hline 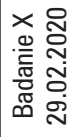 & $\sim$ & $\sim$ & $\sim$ & $\sim$ & $\sim$ & $\sim$ & $\sim$ & $\sim$ & $\sim$ & $N$ & $\sim$ & $\sim$ & $\sim$ & $\sim$ & - & 0 & $N$ & $\bar{m}$ \\
\hline 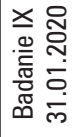 & $\sim$ & $\sim$ & $\sim$ & $\sim$ & $\sim$ & $\sim$ & $\sim$ & $\sim$ & $\sim$ & $\sim$ & $\sim$ & $\sim$ & - & - & - & 0 & $\sim$ & $\stackrel{\infty}{\sim}$ \\
\hline 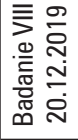 & $\sim$ & $N$ & $\sim$ & $\sim$ & $\sim$ & $\sim$ & $\sim$ & $\sim$ & $\sim$ & $N$ & $\sim$ & $\sim$ & - & - & - & 0 & $\sim$ & $\stackrel{\infty}{\sim}$ \\
\hline 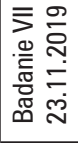 & $\sim$ & $\sim$ & $\sim$ & $\sim$ & $\sim$ & $\sim$ & $\sim$ & $\sim$ & $\sim$ & $\sim$ & $\sim$ & $\sim$ & - & - & - & 0 & $N$ & $\stackrel{\infty}{N}$ \\
\hline 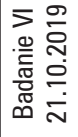 & $\sim$ & $\sim$ & $N$ & $\sim$ & $\sim$ & - & - & - & - & $\sim$ & $\sim$ & $\sim$ & - & - & - & 0 & $\sim$ & $\stackrel{ \pm}{N}$ \\
\hline 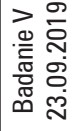 & $\sim$ & $\sim$ & $\sim$ & $\sim$ & $\sim$ & - & - & - & - & $\sim$ & $\sim$ & $\sim$ & - & - & - & 0 & $\sim$ & $\stackrel{ \pm}{N}$ \\
\hline 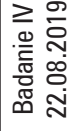 & $\sim$ & $\sim$ & $\sim$ & $\sim$ & $\sim$ & - & - & - & - & $\sim$ & $\sim$ & $\sim$ & - & - & - & 0 & $\sim$ & 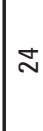 \\
\hline 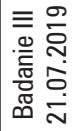 & $\sim$ & $\sim$ & $\sim$ & $\sim$ & $\sim$ & - & - & - & - & $\sim$ & $\sim$ & $\sim$ & - & - & - & 0 & $\sim$ & ন \\
\hline 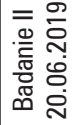 & $\sim$ & $\sim$ & $N$ & $\sim$ & $\sim$ & - & - & - & - & $\sim$ & $\sim$ & $\sim$ & - & - & - & 0 & $\sim$ & 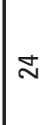 \\
\hline 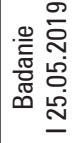 & $\sim$ & $\sim$ & $N$ & $\sim$ & $\sim$ & - & - & - & - & $\sim$ & $\sim$ & $\sim$ & - & - & - & 0 & - & $\nexists$ \\
\hline & 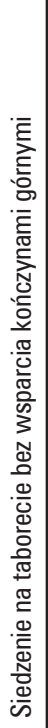 & 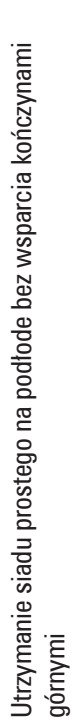 & 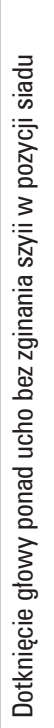 & 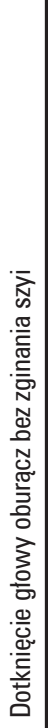 & 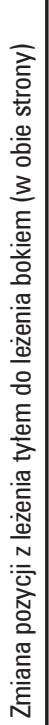 & 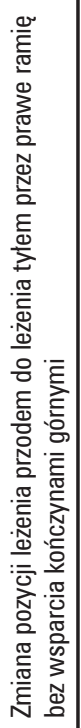 & 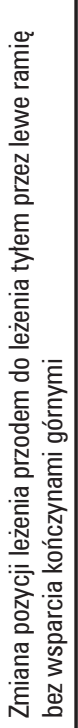 & 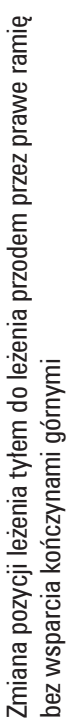 & 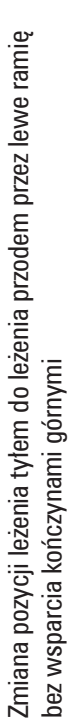 & 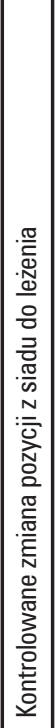 & 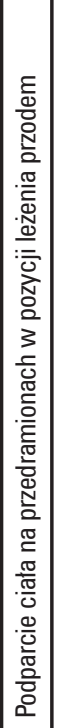 & 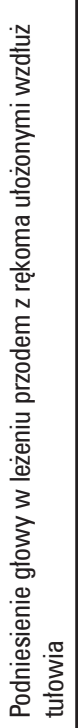 & 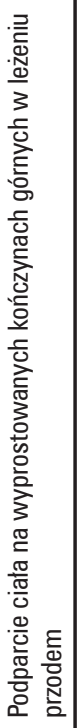 & 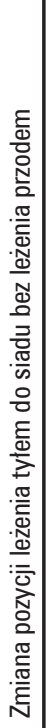 & 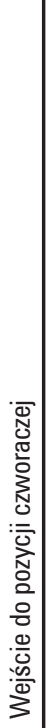 & 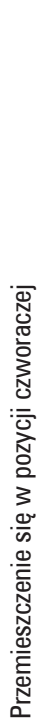 & 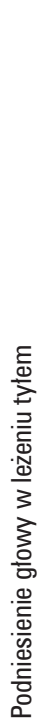 & . \\
\hline
\end{tabular}


[13] O'Hagena J. M., Glanzmanb A. M., McDermott M. P., et al.: An expanded version of the Hammersmith Functional Motor Scale for SMA II and III patients. Neuromuscular Disorders 2007; 17: 693-697.

[14] Main M., Kairon H., Mercuri E., et al.: The Hammersmith functional motor scale for children with spinal muscular atrophy: a scale to test ability and monitor progress in children with limited ambulation. Eur $\mathrm{J}$ Paediatr Neurol 2003; 7: 155-159.

[15] Pera M. C., Coratti G., Mercuri E., et al.: Content validity and clinical meaningfulness of the HFMSE in spinal muscular atrophy. BMC Neurology 2017; 17: 39
[16] Włodarczyk A., Gajewska E.: Przegląd metod oceny funkcjonalnej analizujących motorykę małą i dużą u chorych z rdzeniowym zanikiem mięśni. Child Neurology 2019; 28: 23-26.

[17] Chiriboga C. A., Swoboda K. J., Darras B. T., et al.: Results from a phase 1 study of nusinersen (ISIS-SMN(Rx)) in children with spinal muscular atrophy. Neurology 2016; 86: 890-897. 